\title{
MOISTURE INDUCED DEFORMATIONS IN GLULAM MEMBERS - EXPERIMENTS AND 3-D FINITE ELEMENT MODEL
}

\author{
Henry M. Kiwelu \\ Department of Structural and Construction Engineering, University of Dar es Salaam, \\ P.O. Box 35131, Dar es Salaam, Tanzania \\ Email: hekimaus2005@gmail.com
}

\begin{abstract}
Experiments were performed on scaled glue laminated bending specimens to observe time dependent development of deformations during drying and wetting. Measurements determined changes in the average moisture content and external shape and dimensions between when specimens were placed into constant or variable climates. Alterations in the external shape and dimensions reflected changes in the average value and distribution of moisture and mechanosorptive creep in the glulam. The results are being used to develop a sequentially-coupled three-dimensional hygrothermal Finite Element $(F E)$ model for predicting temporally varying internal strains and external deformations of drying or wetting solid wood structural components. The model implies temporally varying, and eventual steady, state internal stress distributions in members based on elastic and creep compliances that represent wood within glulam as a continuous orthotropic homogenised material. Thus, predictions are consistent with smeared engineering stress analysis methods rather than being a physically correct analogue of how solid wood behaves. This paper discusses limitations of and intended improvements to the FE modelling. Complementary investigations are underway to address other aspects of the hygrothermal behaviour of structural members of wood and other materials (e.g. reinforced concrete) embedded within superstructure frameworks of multi-storey hybrid buildings.
\end{abstract}

Keywords: Beam, creep, finite element model, glulam, heat transfer, hydrothermal strain, mechanosoptive strain, moisture.

\section{INTRODUCTION}

Glued-laminated timber (glulam) is an engineered wood product manufactured by gluing together timber laminates to create relatively large components for structural applications. Like any other structural parts, glulam elements are commonly exposed to wetting by liquid water or air humidity and drying by surrounding air. Usually in building applications direct exposure to liquid water is the result of preventable causes like faulty design, construction errors, lack of

\footnotetext{
${ }^{1}$ Henry Meleki Kiwelu

Structural and Construction Engineering University of Dar es

Salaam, , Email: hekimaus@yahoo.com
}

maintenance and spills. Therefore, focus here is what happens in well designed and constructed buildings within which glulam components are wetted or dried according to temporally varying moisture fluxes at surfaces of components that are exposed to air during and after construction Zhou et al. (2009). In such cases the primary external factors determining the current average moisture content and internal distribution of moisture in glulam are relative humidity $(R H)$ and temperature $(T)$ of surrounding air Eriksson (2005). Temporal variations of $R H$ and $T$ of the air cause temporal variations of average moisture content $\left(u_{a v}\right)$ and gradients within glulam, and affect its physical and mechanical properties. Adverse consequence of initial drying of glulam after 
installation in a building, or moisture cyclic moisture fluxes in service, include component distortions and cracking at exposed surfaces. The distortions reflect development of threedimensional strain gradients that in the extreme case of cracking have reached critical tensile strain values perpendicular to grain Sjodin (2007). To be noted is that although for convenience engineering literature mostly discusses the phenomena in terms of stress levels and gradients, the physical local failure processes are driven by differential strains.

It is suggested in the literature that moisture related distortions of components should be taken in to account during design of timber structures to avoid serviceability and safety related problems (Sjodin, 2005). For example, shrinkage and swelling of timber may cause damage to structural or non-structural parts of systems, including loss of integrity of connections in critical load paths (Sjodin, 2005). Sundström et al. (2011) have shown that heat transfer and mass transfer have coupled effects on behaviours of wood-based construction materials under high-temperature conditions (as can occur during material manufacturing). However, in service temperatures and temperature gradients in glulam components are not likely to be severe, and coupling effect can be expected to be relatively weak. This permits assumption of weak coupling between heat transfer and mass transfer, as implemented by Baronas et al. (2007) in a two-dimensional numerical model of moisture transfer in timber during outdoor storage. In that study temperature everywhere in the timber was assumed to be the same and to vary simultaneously with ambient conditions of surrounding air. Therefore, although the effect of temperature on moisture transfer at the surface was accounted for, moisture flux was the only boundary condition considered. Also, the two-dimensional nature of the representation (Figure 1) meant that only moisture diffusion in the transverse direction was considered as a function of the porosity of timber, in the process smearing differences that exist in the moisture diffusion in radial and tangential directions that characterise the physical structure of timber.
Past above mentioned work by other investigations has demonstrated the importance and conceptual viability of modelling moisture induced deformations of timber construction materials like glulam. However, so far the models created remain preliminary in nature. The remainder of this paper presents initial ideas for a sequentially-coupled threedimensional hygrothermal Finite Element (FE) model for deformation of glulam, and describes some initial experiments supporting creation of such a model.

\section{THEORETICAL FRAMEWORK}

Methods and discussion in this section are predicated on acceptability of engineering stress representations of glulam/timber as a homogenous continuum, and assuming use of softwood species to make glulam.

\section{TIMBER AND GLULAM CHARACTERISTICS}

Timber/glulam has directionally dependent physical and mechanical properties in directions that correspond to the arrangement of cells in tree stems, Figure 1 Forest Products Laboratory, 2001. The anisotropy in the crosssectional plane of stems is due to the growth in radial cell rows which determines unbroken cell wall lines called wood rays. Based on the concept of cylindrical orthotropic structure the radial direction radiates from the pith of any stem. The tangential direction lies normal to the radial direction and tangential to the swept radii that define growth rings in cross-sections. The longitudinal direction corresponds to the pith of any stem. Although trees are imperfect in geometry and other features, the associated true anisotropy is typically ignored. For the purposes of property definitions and for stress analysis it is often assumed that wood is rectilinearly orthotropic with radial, tangential and longitudinal directions being axes of material symmetry. Importance of ignoring the differences between actual tree anisotropy, cylindrical orthotropic structure and rectilinearly orthotropic structure varies from case to case, but can be important for materials like glulam (Koponen et al., 1991). Structural design codes for timber make even greater simplifications such as ignoring directionality 
of material behaviour in the radial-tangential (cross-section) plane and only distinguishing between properties parallel to grain and that perpendicular to grain e.g. Canadian Standards Association (2009). These factors relate, amongst other things, to selection of the way directionality in properties needs to be recognised in prediction of heat and mass transfer, distortions and development of damage in glulam components.

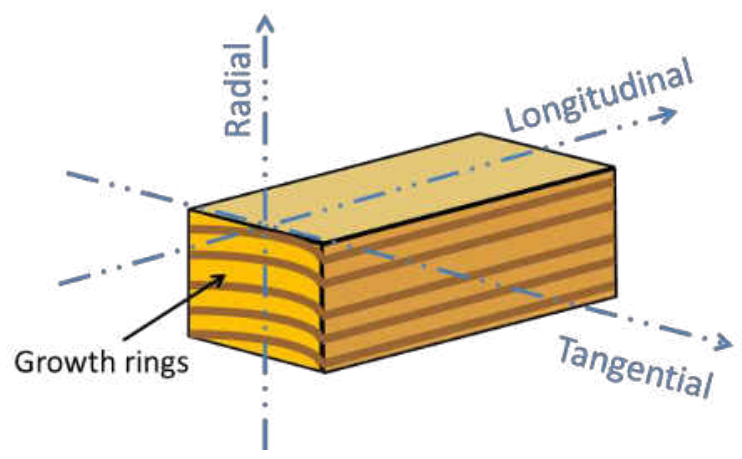

Figure 1: Principal axes of wood with respect to tree stem structure

Moisture in wood components can be found as free water in the cell cavities and as bound water within the cell walls. When only bound water is present, the timber material exchanges moisture with its surroundings continually (Krabbenhøft, 2003). With change in the air humidity wood absorbs or desorbs moisture at unsealed surfaces to the surrounding air or to contacting porous materials. The relationship between the $R H$ and $T$ and moisture content of wood $(u)$ at contact surfaces is a kinetic process that under normal building service conditions is characterised as isothermal sorption with either wood or air the adsorbent and adsorbate mediums. Rates of adsorption or desorption are influenced by the rate of air movement across surfaces of timber/glulam components and if conditions inside building do not approach still air conditions that is a factor to be considered. When $R H$ of surrounding air approaches 100 percent for a sustained period $u$ will reach the fibre-saturation point $(F S P)$. For many wood species the FSP is about 28 percent MC. Conceptually the fibre saturation point defines the state beyond which any increase in $u$ will begin to add only free water to cell cavities, i.e. the point where the amount of bound water held in cell walls is at maximum (Arfvidsson,
1998). However, these are simple heuristic concepts and the true behaviour of timber is much more complex. The question from in an engineering perspective is always where the correct balance lies between simplicity of concepts and need to realistically model the true behaviour, and that is part of the contextual conundrum being addressed by the authors.

\section{MOISTURE MOVEMENT AND HEAT TRANSFER}

Moisture transport in timber is a slow diffusion process that results in moisture and strain gradients. Rates of diffusion primarily depend on $u, T$ and density $(\mathcal{P})$, with rate being higher parallel to the grain than perpendicular to grain (Magistris et al., 2008). Assuming that timber/glulam is a homogeneous and continuous material, Fick's first law applies:

$$
q=-D \frac{d y}{d x}
$$

Where: $q$ is the diffusion flux $\left(\mathrm{kg} \mathrm{m}^{-2} \mathrm{~s}^{-1}\right), D$ is the diffusion coefficient of the material $\left(\mathrm{m}^{2} \mathrm{~s}^{-1}\right)$, $y$ is the moisture concentration $\left(\mathrm{kg} \mathrm{m}^{-3}\right)$, and $x$ the position along the transport direction axes (m). Because when $u$ is less than the FSP physical and mechanical properties of timber change, moisture transport occurs as a nonsteady state process according to Fick's second law. Hence, the one dimensional formulation of the moisture diffusion equation is:

$$
\frac{d u}{d t}=\frac{d}{d x} D(u) \frac{d u}{d x}
$$

Where moisture content $u$ is the weight of water as a percentage of the dry weight of wood, $D(u)$ is the moisture dependent diffusion coefficient $\left(\mathrm{m}^{2} \mathrm{~s}^{-1}\right)$, and $t$ is time $(\mathrm{s})$. The diffusion coefficient describes the rate at which water moves from the interior to the surface. The diffusion coefficient used was $2.88 \mathrm{~mm}^{2} / \mathrm{h}$ (Sjodin, 2007).

At surfaces where moisture can pass between timber and air, equivalence can be assumed to exist between the moisture content of the material surface and the equilibrium moisture content $(E M C)$ associated with $R H$ and $T$. This leads to the boundary condition: 


$$
u_{\text {surf }}=u_{\text {air }}
$$

Where $u_{\text {surf }}$ and $u_{\text {air }}$ are the moisture contents of the timber and air, accounting if appropriate for the circulation conditions of the air. This is called the Drichlet boundary condition (Magistris et al., 2008). However, the alternative Cauchy boundary condition that takes into account mass flux at a material surface is arguably more realistic:

$$
\frac{q_{\eta}}{\mathcal{P}}=s_{u}\left(U_{\text {air }}-U_{\text {surf }}\right)
$$

Where $q_{n}$ represent the moisture flux across the boundary, $\mathcal{P}$ is the density of wood in absolute dry conditions $\left(\mathrm{kg} \mathrm{m}^{-3}\right), s_{u}$ is the emission coefficient of moisture on the surface $\left(\mathrm{m} \mathrm{s}^{-1}\right), s_{u}$ $=3.2 \times 10^{-8} \mathrm{~m} \mathrm{~s}^{-1}$ (Magistris et al., 2008). According to Whale (1988):

$U_{\text {air }}=$
$0.01\left(\frac{-(T+273.15) \ln (1-h)}{0.13(1-(T+273.15 / 647.1))^{6.46}}\right)^{1 /\left[110(T+273.15)^{-0.75}\right]}$

Where $T$ is in degrees Celsius and $\mathrm{h}$ is the relative vapour pressure of the air.

A modified Fourier equation can be assumed to govern conductive temperature changes in wood:

$$
\mathcal{P}_{T} \frac{\partial T}{\partial t}=\nabla\left(\lambda_{T} \nabla K\right)
$$

Where: $\boldsymbol{\nabla}$ is the gradient operator, $C_{T}$ the specific heat of wood, $\lambda_{T}$ thermal conductivity coefficient and $K$ is the wood temperature in ${ }^{\circ} \mathrm{C}$. Effects of convective and radiant heat are normally neglected but can be important in some timber construction situations, and for processes like kiln drying of timber.

Above governing equations are commonly solved using numerical methods and based on finite element approximation representations of timber components (Mirianon, 2008a). In modelling presented later in this paper, equation (3) was adopted rather than equation (4) because moisture transfer resistance at glulam surfaces was not measured by the authors. Importance of this simplification will be evaluated later.

\section{STRAIN AND DEFORMATIONS IN BEAMS}

Under constant climatic conditions the total deformation of glulam beams consists mainly of elastic and creep deformation induced by mechanical forces like self-weight and external loads. The intensiveness of creep deformations depends on the temperature and relative humidity of the surrounding climate at any surfaces. If climatic conditions are not constant, i.e. surrounding $R H$ and $T$ change, two other phenomena occur. The first phenomenon is dilation associated with change in $u_{a v}$ and glulam temperature, and distortion associated with internal gradients $u$ and glulam temperature. The second phenomenon is coupling effects of mechanical forces and changes in $u$, i.e. what are often termed mechanosorptive effects. Because of the temporal nature of the involved processes resulting strains and deformations are referred to as mechanosorptive creep (Mirianon et al. 2008a). The coupled nature of physical processes in glulam components subjected to variable climates can be analysed based on prediction of effects of non-stationary heat and water transfers within them.

Total strain vector $\varepsilon_{\text {total }}$ can be divided into elastic strain $\varepsilon_{\theta}$, thermal induced strain $\varepsilon_{T}$, moisture induced strain $\varepsilon_{u}$, creep strain $\varepsilon_{c r}$, and mechanosorptive stain $\varepsilon_{m s}$ :

$\varepsilon_{\text {total }}=\varepsilon_{e}+\varepsilon_{T}+\varepsilon_{u}+\varepsilon_{c r}+\varepsilon_{m s}$

The component $\varepsilon_{c r}$ is creep strain that would occur under constant climatic conditions, and component $\varepsilon_{m s}$ is the incremental strain associated with climatic variations.

Following from Hooke's law, the elastic strain is:

$$
\varepsilon_{e}=S_{e} \sigma
$$

Where $\sigma$ is the stress vector and $S_{e}$ is the compliance matrix. 


$$
\mathrm{S}_{\mathrm{e}}=\left[\begin{array}{cccccc}
\frac{1}{E_{r}} & \frac{-v_{t r}}{E_{t}} & \frac{-v_{l r}}{E_{r}} & 0 & 0 & 0 \\
\frac{-v_{r t}}{E_{r}} & \frac{1}{E_{t}} & \frac{-v_{l t}}{E_{I}} & 0 & 0 & 0 \\
\frac{-v_{r I}}{E_{r}} & \frac{-v_{t I}}{E_{t}} & \frac{1}{E_{I}} & 0 & 0 & 0 \\
0 & 0 & 0 & \frac{1}{G_{r t}} & 0 & 0 \\
0 & 0 & 0 & 0 & \frac{1}{G_{r I}} & 0 \\
0 & 0 & 0 & 0 & 0 & \frac{1}{G_{t I}}
\end{array}\right]
$$

Where in $E_{r}, E_{t}$ and $E_{l}$ are of elastic moduli of wood in radial, tangential and longitudinal directions respectively; $G_{r t}, G_{r l}, G_{t l}$ are shear moduli; and $v_{r t}, v_{r l}$ and $v_{t l}$ are Poisson's ratios. Elastic moduli can sensible be assumed to be proportional to the density, temperature, and $u$ of wood (Koponen et al., 1991):

$E_{i}=E_{i, r e f}\left[1+\alpha_{1}\left(\mathcal{P}-\mathcal{P}_{r e f}\right)+\alpha_{2}(K-\right.$ $\left.\left.K_{r e f}\right)+\alpha_{3}\left(u-u_{r e f}\right)\right]$

Where $E_{i, r e f}$ is the modulus of elasticity for direction $i$ at reference conditions of $\mathcal{P}, K$ and $u$; and $\alpha_{i}$ are that adjust for unitary deviations from reference conditions of the variables that affect elastic moduli. The same logic applies to adjustment for $G_{i j}$ values from reference to actual conditions.

Thermal strain can be calculated as:

$$
\varepsilon_{T}=\alpha_{T} \Delta K
$$

Where $\alpha_{T}$ is the thermal expansion coefficient vector, and $\Delta \mathrm{K}$ is the change in temperature.

Moisture induced strain can be estimated by:

$$
\varepsilon_{u}=\alpha_{u} \Delta u .
$$

Where $\alpha_{\mathrm{u}}$ is the dilatory coefficient vector and $\Delta \mathrm{u}$ is change of moisture content.

Creep strain can be calculated as:

$$
\varepsilon_{c r}=\int_{0}^{t} S_{c r}(t) \frac{\partial \sigma(t)}{\partial t} d t
$$

Where $S_{c r}(t)$ is the creep compliance matrix, terms of which are calibrated by various methods based on experiments (Mirianon et al., 2008a).
The mechanosorptive creep rate can be assumed to depend on the rate of change of $R H$ and the stress level and the histories of those variables [13, 14], leading to:

$$
\varepsilon_{m s}=\int_{0}^{t} S_{m s} \sigma \frac{\partial u}{\partial t} d t
$$

Where $S_{\mathrm{ms}}$ is the mechanosorptive compliance matrix. Again terms of the matrix are calibrated by various methods based on experiments, and it has been suggested that values in $\mathrm{S}_{\mathrm{ms}}$ should be conditional to $u$ (Smith et al., 2003)

$$
\begin{aligned}
& S_{m s}= \begin{cases}S_{m s}^{+} & u>0 \\
S_{m s}^{-} & u \leq 0\end{cases} \\
& S_{m s}=\begin{array}{cccccc}
m_{L} & -\mu_{R L} m_{R}-\mu_{T L} m_{T} & 0 & 0 & 0 \\
-\mu_{L R} m_{L} & m_{R} & -\mu_{R T} m_{R} & 0 & 0 & 0 \\
-\mu_{L T} m_{L} & -\mu_{R T} m_{R} & m_{T} & 0 & 0 & 0 \\
0 & 0 & 0 & m_{L R} & 0 & 0 \\
0 & 0 & 0 & 0 & m_{L T} & 0 \\
0 & 0 & 0 & 0 & 0 & m_{R T}
\end{array}
\end{aligned}
$$

Where $\mathrm{m}_{\mathrm{L}}, \mathrm{m}_{\mathrm{R}}$ and $\mathrm{m}_{\mathrm{T}}$ are mechanosorption coefficients in the orthotropic directions i.e. Longitudinal, Radial and tangential, respectively.

Above equations follow the approach of Mirianon et al. (2008a; 2008b). The assumption of uncoupled affects and linearity of adjustments underpinning equations (6) to (15) are not believed to be crucial departures from actual behaviour of glulam installed in building having normal interior climates.

\section{SHRINKAGE AND SWELLING OF WOOD}

Moisture shrinkage/expansion coefficients of glulam depend on the positions and directions relative to the pith of tree stems from which laminations were cut, and the homogenizing effects of assembling laminations to create components. Coefficients depend on many factors including the wood species, the value of $u$ at which moisture change began, and the increment of moisture change involved. For spruce species, which are commonly used in Canada, and elsewhere, for making glulam, the average tangential shrinkage from the FSP to oven-dry is around 7 to $8 \%$, while 
corresponding average radial shrinkage and longitudinal shrinkages are about $4 \%$ and between 0.1 to $0.2 \%$ respectively. Such values can be used as the basis of the dilatory coefficient vector $\alpha_{u}$ in equation (11). Refinements are possible to recognize factors like departure of the shrinkage/expansion from linear dependence on the current value of $u$ and dependence on the moisture history by, for example, applying equation (11) piecewise.

\section{EXPERIMENTS}

As already indicated, experiments described here were designed to support the development of a three-dimensional finite element model capable of predicting temporally varying internal strains and external deformations of drying or wetted glulam structural elements with or without external applied forces. Those experiments were relatively simple and small scale, and are a precursor to complex experiments necessary to rigorously establish how glulam components interact with components of other materials commonly found in large hybrid building superstructures.

Eight scaled straight glulam members of 60 $\mathrm{mm}$ depth by $40 \mathrm{~mm}$ width by about $2.2 \mathrm{~m}$ long were made from $10 \mathrm{~mm}$ thick spruce laminates glued together with Phenol Resorcinol Formaldehyde (PRF) adhesive. The laminations were cut from commercially produced lumber that was nominally air dry $\left(u_{a v}\right.$ around $\left.15 \%\right)$. After fabrication specimens were stored in a conditioning chamber for four weeks at $20^{\circ} \mathrm{C}$ and $65 \% R H$ until they attained an EMC of about $12 \%$ prior to testing. This was to nominally simulate conditions in which full-size glulam components typically arrive at construction sites.

Two control specimens were kept in the constant environment (i.e. 12\% EMC) and the six others were tested in a specially built environmental chamber. The special chamber has the capability to alter the climate ( $T$ and $R H$ ) of air surrounding specimens while they were supported in different ways and/or subjected to effects of external loads. Table 1 lists the combinations of test conditions investigated.
Table 1: Combination of test variables

\begin{tabular}{ccc}
\hline Specimens & Loaded & Climate \\
\hline ULC1, ULC2 & No & Constant* \\
\hline LC1, LC2 & Yes** & Constant \\
\hline ULV1, ULV2 & No & Variable \\
\hline LV1, LV2 & Yes & Variable \\
\hline$* 20^{\circ} \mathrm{C}, 65 \%$ RH, & $* *$ As Figure 3.
\end{tabular}

Two experiment arrangements were employed. One arrangement represented horizontal members with nominally zero external loading effects, i.e. supported underneath so that selfweight could not produce bending deformations, Figure 2 (a). This situation determined the unloaded response of the scaled glulam under constant and variable climates. The other arrangements represented horizontal members with external loading effects, i.e. selfweight plus external loads that caused bending deformations, Figures 2(b) and 3. Magnitudes of the applied loads were self-weight of 11.06 $\mathrm{N}$ per $\mathrm{m}$ and concentrated forces of $50 \mathrm{~N}$ each (Figure 4). This resulted in a stress levels (circa 0.15 to 0.20 of ultimate capacity) comparable to those existing in superstructure systems controlled by deflections, as is expected for many large and tall hybrid buildings.

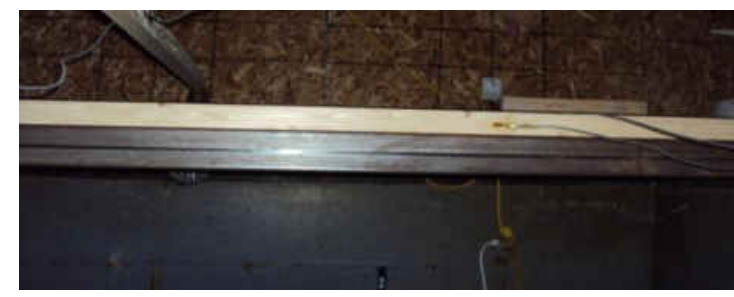

(a)

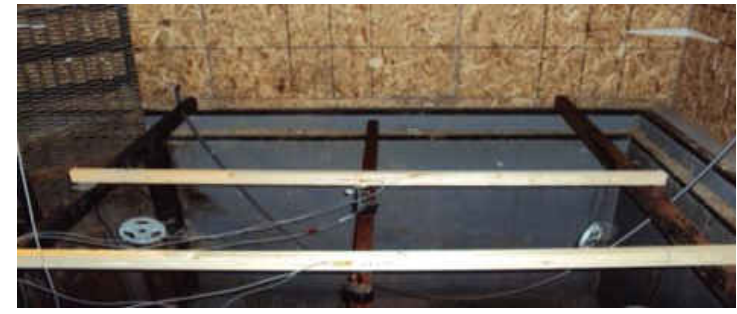

(b)

Figure 2: (a) Unloaded and (b) Loaded test arrangements in the variable climate 


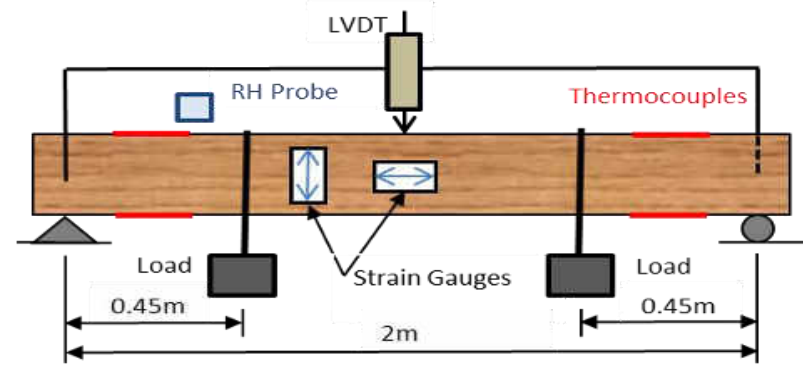

Figure 3: Loaded test arrangement - schematic with respect to strain gauge positions

Specimens tested in a variable climate were subjected to cyclical variations in the $R H$ of surrounding air at a constant air temperature of $20^{\circ} \mathrm{C}$. Initially average daily relative humidity of the air varied from 55 to 95 percent based on a 1 week cycle length for 5 cycles. Then $R H$ was then varied from 65 to 90 percent over one longer cycle of about 2 months, shown in Figure 4. Finally, specimens were allowed to equilibrate in a constant climate of $20^{\circ} \mathrm{C}$ and $68 \% R H$. The logic of the chosen variable climate was to simulate climatic fluctuations that might occur inside heated buildings.

As appropriate, vertical displacements, and longitudinal and transverse dilatory deformations of specimens were measured every minute using electronic devices, as illustrated schematically in Figure 3. Average dilations were measures by strain gauges glued to specimens as shown in the figure. The $R H$ of air in the chamber with variable climate was taken to be the average of measurements from four relative humidity probes at different locations within the chamber (with minimal variations observed between measuring locations). Air temperature was measured at specimen surfaces using four thermocouples as shown in Figure 3. Both $R H$ and $T$ were also recorded every minute. As shown in Figure 4, the actual air temperature in the chamber with a variable climate was slightly above the target value of $20^{\circ} \mathrm{C}$. Figure 5 and 6 shows respectively selected total strain results for the two unloaded and loaded specimens in the variable climate. Those responses represent longitudinal strain at the tension face near midspan, and perpendicular to grain strain at the mid-span. In the case of the perpendicular to grain strains the measuring direction was parallel to the depth. The windowed time interval encompassed the five weeks during which $R H$ cycled between $65 \%$ and $90 \%$, which was period of net wetting of the specimens. As previously indicated, $\boldsymbol{\varepsilon}_{\text {total }}$ contains a number of important components, that with the exception of $\boldsymbol{\varepsilon}_{\mathrm{e}}$ are not separable without a supporting analytical framework/model. For that reason, it is not meaningful to draw any generalised conclusions about temporally varying strains and external deformations of glulam components.

Experiments done so far are not sufficient on their own for robust verification of any hydrothermal or creep response model. Instead, as previously alluded they are simply providing insights into approaches that need to be adopted during modelling.

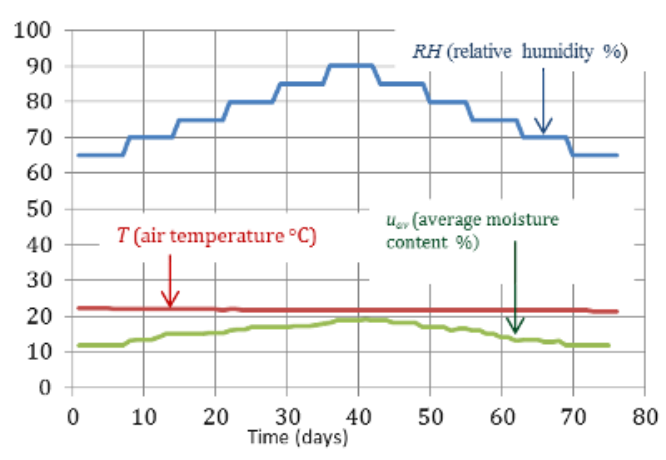

Figure 4: Air temperature (T), relative humidity $(R H)$ and glulam average moisture content $\left(u_{a v}\right)$ variable climate experiments

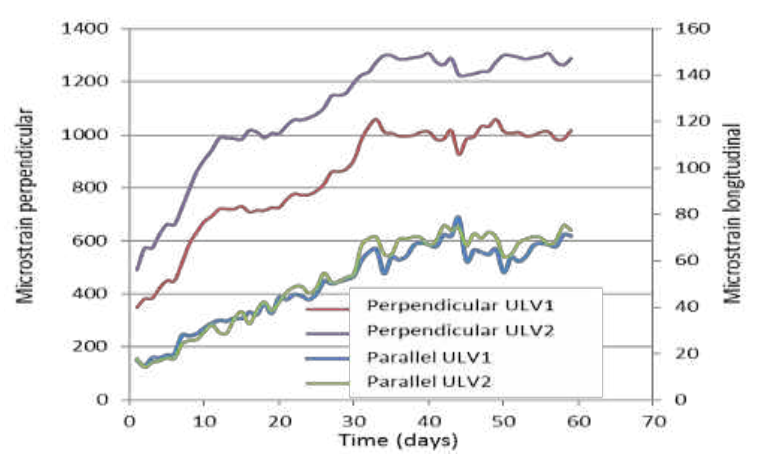

Figure 5: Unloaded specimens (specimens $U L V 1 \& U L V 2)$

\section{FINITE ELEMENT ANALYSIS}

The calculation of moisture induced stresses by means of numerical simulations is well established. The commonly applied basic material model is based on a strain rate 
formulation. Two classes of models appear in the literature for predicting deformation of timber/wood. The first class is an orthotropic continuum mechanics model that smears the effects of microstructure, and the second class is discrete mechanics models that realistically represent microstructural behaviour (Mirianon et al., 2008b). The approach taken here is the former as an implementation of concepts discussed in Section 2.

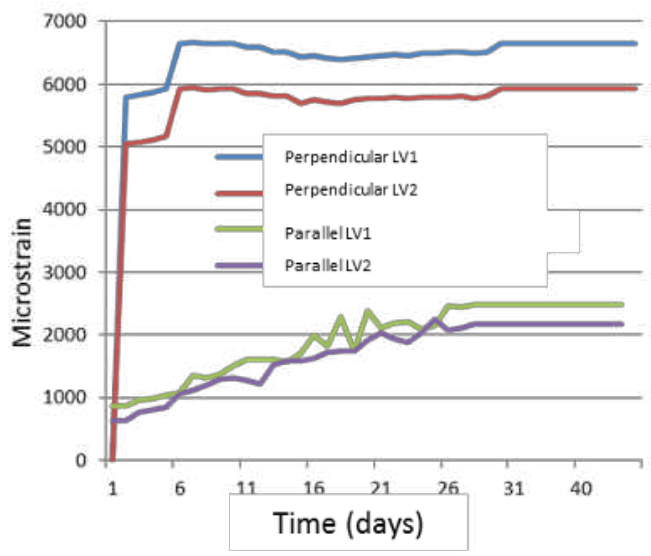

Figure 6: Total strain, $\varepsilon_{\text {total }}$, responses for loaded specimens in a variable climate (specimens LV1 \& LV2)

\section{MODEL DESCRIPTION}

The ABAQUS finite element software package Mirianon et al. (2008b), was used as the modelling medium for coupled mass diffusion analysis, consisting of a coupled temperaturedisplacement analysis followed by a mass diffusion analysis. ABAQUS was selected because it can perform sequentially coupled thermo-mechanical mass diffusion analysis. Material properties in Table 2 were selected based on assuming a three-dimensional rectilinear orthotropic material structure (Mirianon et al., 2008b). Diffusivity of mass was assumed to be the same in longitudinal and transverse directions, as an initial approach with recognized limitations.

At present, there are no readymade wood models in ABAQUS for time dependent analysis, however there is a way to create own material models. ABAQUS uses several subroutines, programmed in FORTRAN language, to permit the user to define his own material model. In our case, it was necessary to use the UMAT subroutine to implement the rheological model of wood, and the DFLUX subroutine to define the flow of moisture on the surface of the wood (Ormarsson, 1999).

To facilitate the convergence of the analysis, a few alternative methods can be used. The most important is the smoothing of the applied loads, which includes the mechanical loads and the relative humidity. The ABAQUS Analysis Userís Manual (ABAQUS 2003) gives good advices about curves smoothing; it presents how ABAQUS changes an instantaneous load change into a ramp load change or into a so called smooth load change. The same methods can be used in the DFLUX subroutine to define the relative humidity.

Table 2: Diffusion values used in the analysis

\begin{tabular}{|c|c|c|c|}
\hline $\begin{array}{c}\text { Moisture } \\
\text { content } \\
(\mathrm{MC})\end{array}$ & $\begin{array}{c}\text { Radial } \\
\text { diffusion } \\
\text { coefficient } \\
{\left[\mathrm{m}^{2} / \mathrm{h}\right]}\end{array}$ & $\begin{array}{c}\text { Tangential } \\
\text { diffusion } \\
\text { coefficient } \\
{\left[\mathrm{m}^{2} / \mathrm{h}\right]}\end{array}$ & $\begin{array}{c}\text { Longitudinal } \\
\text { diffusion } \\
\text { coefficient } \\
{\left[\mathrm{m}^{2} / \mathrm{h}\right]}\end{array}$ \\
\hline $12 \%$ & 0.0006690 & 0.0006690 & 0.00454 \\
\hline $15 \%$ & 0.007028 & 0.0006908 & 0.00365 \\
\hline $18 \%$ & 0.0008026 & 0.0008026 & 0.00307 \\
\hline $20 \%$ & 0.0009690 & 0.0009690 & 0.00210 \\
\hline
\end{tabular}

The finite element mesh used to represent the scaled glulam members described in Section 3 is shown in Figure 7. Type C3D8T eight-node linear hexahedron thermally coupled brick elements with tri-linear displacement and temperature variations for coupled displacement and temperature analysis were used, with 4800 elements in total. This element was selected to exploit the similarity of governing equations for temperature and moisture transport, which enabled the governing constant for a temperature field to be replaced by the effective coefficient of diffusion for mass transport. Physical boundary conditions used in the analysis discussed here were simple end supports and concentrated loads shown in Figure 3. Boundary conditions for moisture transfer were that the glulam surface moisture flux and temperature matched temporally varying values measured during the variable climate experiments. Initial glulam moisture content and temperature were taken to be uniform and equal to $12 \%$ and $20^{\circ} \mathrm{C}$, respectively. 
Equivalent stresses and temperatures from the temperature-displacement analysis were written to result files as averaged nodal and nodal values respectively. Subsequently those results were used during a mass diffusion analysis to provide 'driving mechanisms' for mass diffusion. The primary outputs were prediction of the evolution of moisture gradients, bending deflections and specimen dilations.

To note is that at present ABAQUS has no library modelling capabilities specific to time dependent analysis of wood components. It is possible for users to create their own material specific subroutine models, but so far the authors have not done so. What is reported here is therefore simply the first stage of analysing coupled mass diffusion analysis in glulam. One of the next steps will be for the authors to either write their own material specific subroutines or undertake that task in collaboration with international experts.

Table 3: Assumed glulam material properties

\begin{tabular}{|c|c|}
\hline Parameter & Value \\
\hline$\alpha_{u}$ & 0.13 \\
\hline$D(u)$ & $2.886 \times 10^{-7} \mathrm{~m} / \mathrm{s}$ \\
\hline$C_{t}$ & $1170[15(1+\mathrm{T} / 100)]^{0.2} \mathrm{~J} / \mathrm{kg} /{ }^{\circ} \mathrm{C}$. \\
\hline $\mathcal{P}$ & $450 \mathrm{~kg} / \mathrm{m}^{3}$ \\
\hline$E_{l}$ & $12000 \mathrm{MPa}$ \\
\hline$E_{r}$ & $900 \mathrm{MPa}$ \\
\hline$E_{t}$ & $500 \mathrm{MPa}$ \\
\hline$G_{r t}$ & $40 \mathrm{MPa}$ \\
\hline $\mathrm{G}_{\mathrm{rl}}$ & $700 \mathrm{MPa}$ \\
\hline $\mathrm{G}_{\mathrm{tl}}$ & $700 \mathrm{MPa}$ \\
\hline$\alpha_{\mathrm{T}}$ & 0.13 \\
\hline$\alpha_{1}$ & 0.27 \\
\hline$\alpha_{2}$ & 0.005 \\
\hline$v_{r t}$ & 0.55 \\
\hline$v_{r l}$ & 0.038 \\
\hline$v_{r t}$ & 0.015 \\
\hline
\end{tabular}

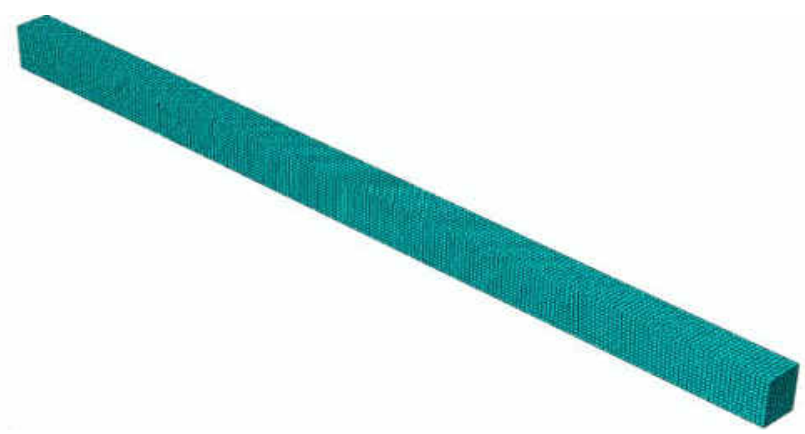

FE mesh

Figure 7: Mesh of 8-node type C3D8T brick elements

Currently identifiable deficiencies in the modelling include:

- Neglect of glue layers at interfaces between laminations.

- Neglect of systemic (e.g. growth rings, density) and random (e.g., knots, finger joints) material homogeneity and discontinuities (e.g. drying cracks) characteristic of commercial glulam.

- Neglect of directional dependence of mass diffusion relative to axes of material symmetry.

- Simplification of initial moisture and temperature conditions.

Addressing each of these, and other, model shortcomings will be considerable tasks.

\section{MODELLING RESULTS}

Figure 8 shows typical predicted surface strains and deflection shapes, for a loaded specimen in a variable climate.

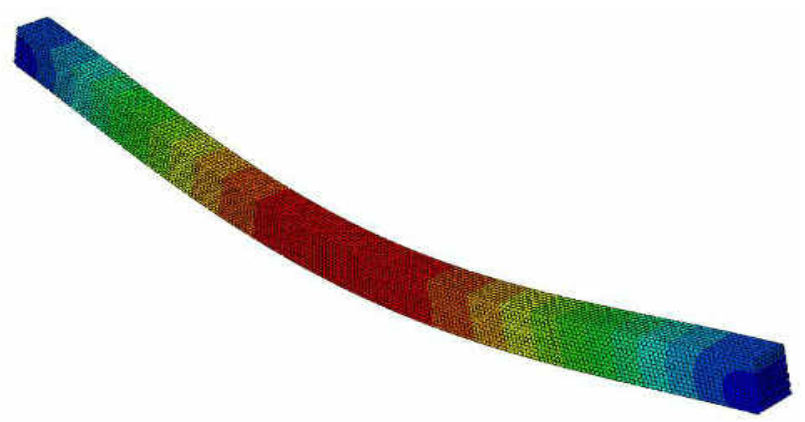

Figure 8: Predicted responses after loading 


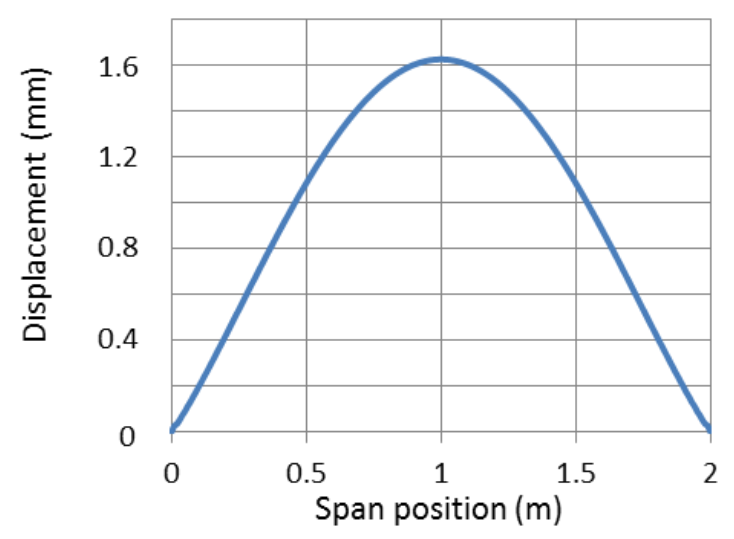

Figure 9: Bending displacement due to self weight and external loading

Figure 9 shows a typical bending deflection distribution obtained from FE modelling. Interestingly, it was found that the calculated mid-span elastic displacement was $1.19 \mathrm{~mm}$ and the complete ABAQUS model prediction was $1.62 \mathrm{~mm}$. The difference in the values reflects the influence of creep strains. Preliminary comparison of FE predictions with experimental data gives some confidence in the modelling techniques. However, all FE model results presented here represented only the initial step of thermo mechanical analysis. Because of that, and given various uncertainties about the robustness of the model and the limited nature of the experiments to date, drawing other than the broadest of conclusions now would be less than circumspect.

Complementary investigations are underway to address other aspects of hydrothermal behaviour of structural members of glulam and other materials (e.g. reinforced concrete) embedded within superstructure frameworks of multi-storey hybrid buildings.

\section{CONCLUSIONS}

Even though what has been done so far by the authors, it is clearly feasible to predict temporally varying internal strains and external deformations of drying or wetting glulam structural components via continuum finite element modelling techniques. The employed framework of sequentially-coupled threedimensional hydrothermal modelling shows promise as the basis of a robust engineering tool for predicting, and therefore being able to counteract, adverse deformations and material incompatibilities that can exist within hybrid building systems.

\section{REFERENCES}

Arfvidsson J. (1998). Moisture Transport in Porous Media. Doctoral Thesis, Lund University, Lund, Sweden.

Baronas R., Ivanauskas F., Juodeikient I. and Kajalavieius A. (2001). Modelling of moisture movementin wood during outdoor storage Nonlinear Analysis Journal of Modelling and Control, 6:3-14.

Canadian Standards Association: Engineering design in wood (2009). Standard 086-09, CSA, Toronto, Canada.

Eriksson J. (2005). Moisture transport and moisture induced distortions in timber - an experimental and numerical study. $P h D$ Thesis, Chalmers University of Technology, Gothenburg, Sweden.

Forest Products Laboratory (2011). Wood as an engineering material. Handbook, Washington, DC: US Department of Agriculture, 466p.

Hibbitt, Karlsson and Sorensen Inc. (2011). ABAQUS. Standard User's Manual Version 6.9, Pawtucket, Rhode Island, USA.

Koponen S., Toratti T. and Kanerva P. (1991). Modelling elastic and shrinkage properties of wood based on cell structure. Wood Science and Technology, 25:25-32.

Krabbenhøft K. (2003). Moisture transport in wood - A study of physical-mathematical models and their numerical implementation. PhD Thesis, Technical University of Denmark, Lyngby, Denmark.

Magistris F. and Salmen L. (2008). Finite Element modelling of wood cell deformation transverse to the fibre axis. Nordic Pulp and Paper Research Journal, 23(2): 240-246.

Mirianon F., Fortino S. and Toratti T. (2008a). A method to model wood by using ABAQUS finite element software: Part 1 constitutive model and computational details. Publications 687, Technical Research Centre, Espoo, Finland.

Mirianon F., Fortino S. and Toratti T. (2008b). A method to model wood by using 
ABAQUS finite element software: Part 2 Application to dowel type connections. Publications 690, Technical Research Centre, Espoo, Finland.

Ormarsson S. (1999). Numerical analysis of moisture-related distortions in sawn timber. PhD Thesis, Chalmers University of Technology, Gothenburg, Sweden.

Sjodin J. (2007). Strength and moisture aspect of steel -timber dowel joint in glulam structures - An experimental and Numerical study. Doctoral Thesis, Växjö University, Sweden.

Sundström T., Kevarinmäki A., Fortino S. and Toratti T. (2011). Shear resistance of glulam beams under varying humidity conditions. VTT Working Papers, 14597683: 125-137.

Smith I., Landis E. and Gong M. (2003). Fracture and fatigue in wood. John Wiley and Sons, Chichester, UK.

Zhou Z.H., Zhu E.C., Fortino S. and Toratti T. (2009). Modelling the hydrothermal stress in curved glulam beams. Journal of Strain Analysis, 45:129-140. 